NBER WORKING PAPER SERIES

\title{
ESTIMATES OF CROWD-OUT FROM A PUBLIC HEALTH INSURANCE EXPANSION USING ADMINISTRATIVE DATA
}

\author{
Laura Dague \\ Thomas DeLeire \\ Donna Friedsam \\ Daphne Kuo \\ Lindsey Leininger \\ Sarah Meier \\ Kristen Voskuil \\ Working Paper 17009 \\ http://www.nber.org/papers/w17009
}

\author{
NATIONAL BUREAU OF ECONOMIC RESEARCH \\ 1050 Massachusetts Avenue \\ Cambridge, MA 02138
}

May 2011

We gratefully acknowledge the financial support of Wisconsin's Department of Health Services and the helpful comments of Amanda Kowalski, Maximilian D Schmeiser, and participants at the 2010 Annual Health Economics Conference and the 2011 ASSA conference. The views expressed herein are those of the authors and do not necessarily reflect the views of the National Bureau of Economic Research.

NBER working papers are circulated for discussion and comment purposes. They have not been peerreviewed or been subject to the review by the NBER Board of Directors that accompanies official NBER publications.

(C) 2011 by Laura Dague, Thomas DeLeire, Donna Friedsam, Daphne Kuo, Lindsey Leininger, Sarah Meier, and Kristen Voskuil. All rights reserved. Short sections of text, not to exceed two paragraphs, may be quoted without explicit permission provided that full credit, including ()$^{\text {notice, }}$, is given to the source. 
Estimates of Crowd-Out from a Public Health Insurance Expansion Using Administrative Data

Laura Dague, Thomas DeLeire, Donna Friedsam, Daphne Kuo, Lindsey Leininger, Sarah Meier, and Kristen Voskuil

NBER Working Paper No. 17009

May 2011

JEL No. I18

\author{
ABSTRACT \\ We use a combination of administrative and survey data to estimate the fraction of individuals newly \\ enrolled in public health coverage (Wisconsin's combined Medicaid and CHIP program) that had access \\ to private, employer-sponsored health insurance at the time of their enrollment and the fraction that \\ dropped this coverage. We estimate that after expansion of eligibility for public coverage, approximately \\ $20 \%$ of new enrollees had access to private health insurance at the time of enrollment and that only \\ $8 \%$ dropped this coverage (with the remaining $12 \%$ having both private and public coverage). We \\ also identify an "upper bound" estimate, which suggests that the percentage of new enrollees with \\ private insurance coverage at the time of enrollment is, at most, 27\%. These estimates of crowd-out \\ are relatively low compared with estimates from the literature based on Medicaid and CHIP expansions, \\ although based both on different data and on a different method. \\ ] \\ Laura Dague \\ Department of Economics \\ University of Wisconsin-Madison \\ 1180 Observatory Drive \\ Madison, WI 53706-1393 \\ dague@wisc.edu \\ Thomas DeLeire \\ La Follette School of Public Affairs \\ University of Wisconsin-Madison \\ 1225 Observatory Drive \\ Madison, WI 53706 \\ and NBER \\ deleire@wisc.edu \\ Donna Friedsam \\ UW Population Health Institute \\ University of Wisconsin-Madison \\ 610 Walnut Street \\ Madison, WI 53726 \\ dafriedsam@wisc.edu \\ Daphne Kuo \\ UW Population Health Institute \\ University of Wisconsin-Madison \\ 610 Walnut Street \\ Madison, WI 53726 \\ dkuo@ssc.wisc.edu \\ Lindsey Leininger \\ Chapin Hall at the University of Chicago \\ 1313 E. 60th Street \\ Chicago, IL 60637 \\ lleininger@chapinhall.org \\ Sarah Meier \\ Department of Population Health Sciences \\ 8 QIYHUMMIRI: LMRQMQ]0 DCIRQ \\ 610 Walnut Street \\ Madison, WI 53726 \\ skmeier@wisc.edu \\ Kristen Voskuil \\ 8 : प3RSXDURQ+ HDOK, QMWM \\ University of Wisconsin-Madison \\ 610 Walnut Street \\ Madison, WI 53726 \\ krvoskuil@wisc.edu
}




\section{Introduction}

The 2010 Patient Protection and Affordable Care Act (ACA) is expected to increase health insurance coverage largely through expansions to Medicaid (CBO, 2009). The extent of declines in uninsured rates depends on the target efficiency of the Medicaid expansions — that is, the percentage of individuals that are newly covered by public programs that previously had private insurance. Reductions in the number of uninsured individuals may not be the only objective of expansions in eligibility for public insurance, as some programs also seek to improve the quality of coverage in terms of benefits and affordability (Dorn, 2011). But the policy debate continues to focus on the degree to which expansions efficiently reach the uninsured, and do not promote substitution of public coverage for private.

To date, the economics literature has provided a wide range of estimates of crowd-out, measuring the percentage of newly eligible public insurance enrollees that would have otherwise held private insurance. These estimates vary because of differing methods, data, and time periods or programs that have been examined. A summary of the literature produced the oftcited assertion that the crowd-out rate associated with previous public health insurance program expansions in the U.S. lies between 25 and 50\% (CBO, 2007).

Our paper contributes to this literature on the crowd-out of private coverage from public health insurance program expansions in two ways. First, we use longitudinal administrative data from Wisconsin's public health insurance programs (called BadgerCare Plus, or BC+) that covers the period from January 2006 to November 2009 during which the program was expanded. Administrative data have many advantages relative to survey data when tracking public program enrollment. We observe the universe of enrollees in public coverage as well as their families. We can directly observe the private insurance status for the length of enrollment for almost $90 \%$ of enrollees, and for the remainder (who are at self-insured firms) we are able to 
impute coverage status. The use of administrative data in this study allows us to accurately capture movements between private and public coverage for individuals who enroll in public coverage, which has not been previously possible. We are also able to observe work transitions that may be associated with losses of coverage. The size of our administrative sample also allows us to examine crowd-out rates by subgroup, including age, income, and geographic location. To our knowledge, no previous study has used administrative databases to estimate the prior private insurance coverage of enrollees into public coverage.

Second, the expansion in public coverage we examine is to populations that are not typically covered by Medicaid or the Children's Health Insurance Program (CHIP). Thus, the estimates we provide of the proportion of enrollees into $\mathrm{BC}+$ that previously held private insurance will be informative as Medicaid expansions move forward under national health reform. Specifically, we study an elimination of income limits for children's coverage, the expansion of income eligibility of parents and caretaker adults from $185 \%$ and $44 \%$ of the federal poverty level (FPL), respectively, up to $200 \%$ of the federal poverty level (FPL), subject to some restrictions regarding insurance status, and a complete lifting of any crowd-out-related restrictions for those below $150 \%$ FPL. While the majority of the population made newly eligible under the $\mathrm{BC}+$ reforms had higher incomes than the population slated to become Medicaid-eligible under the 2010 Patient Protection and Affordable Care Act (ACA), the BC+ crowd-out estimates remain relevant to the current national debate. First, the great majority of the newly enrolled populations in $\mathrm{BC}+$ had incomes under $150 \%$ FPL, closely mirroring the likely ACA expansion population. Moreover, the maintenance of effort requirements put in place with ACA's passage - requiring states to at minimum uphold current Medicaid eligibility levels have come under fire by some state officials hoping to cut Medicaid costs by eliminating 
Estimates of Crowd-Out from Administrative Data

eligibility for relatively higher-income populations (Serafini and Appleby 2011; Solomon 2011). Understanding the prevalence of crowd-out for the subgroup of higher-income BC + enrollees should inform what could be a perennially contentious national debate.

Our results suggest that far fewer individuals were displaced from private coverage than generally thought. We find an overall crowd-out rate of $19.9 \%$, measured as the fraction of enrollees who had private coverage at the time of enrollment between April 2008 and November 2009. This rate is much lower than most estimates in the literature on the CHIP-era expansions. Our results indicate that higher-income individuals are more likely to have private insurance, consistent with the literature. However, even among enrollees with incomes of over 300\% FPL, we find an estimate of $37.0 \%$ on this measure of crowd-out. When we use the longitudinal nature of our data to consider as crowded-out only those individuals who dropped their private insurance within six months of enrollment, we find an overall rate of $8.4 \%$ and only $20.0 \%$ in the highest income eligibility brackets.

The paper proceeds as follows. Section 2 discusses the established methods for understanding and measuring crowd-out and how our approach fits in to this context. Section 3 describes the unique combination of administrative and survey data sources we use for our analysis. Section 4 specifies the methods we use to measure crowd-out and section 5 presents our results. Finally, section 6 discusses the implications of our results for policy and our conclusions.

\section{Background}

Interest in the potential displacement of private insurance coverage by public health programs increased with the expansions of state Medicaid programs in the late 1980s and early 
1990s. Traditionally, Medicaid coverage had been tied to eligibility for AFDC cash assistance, but the 1996 welfare reform law and expansion in Medicaid eligibility severed this link and allowed family types and income categories that were not necessarily welfare eligible to gain public health insurance coverage. Enrollment in public health insurance programs grew significantly with these changes, raising concerns among some policy-makers about the extent to which public coverage was substituting for, or "crowding out," private health insurance.

Crowd-out occurs when private insurance coverage is lower than it would have been in the absence of the public program- for example, if people substitute public for private coverage or employers reduce their insurance offerings If people would otherwise have become uninsured, enrolling in a public program does not constitute crowd-out.

Early work by Cutler and Gruber (1996) measures crowd-out occurring in response to the Medicaid expansions targeting poor younger children during the years 1987 and 1992. They use state variation in eligibility (due to variation in policy implementation), cross-sectional data from the Current Population Survey (CPS), and an instrumental variable framework (where simulated eligibility based on the state-level eligibility rates using a national sample serves as the instrument for actual eligibility), and conclude that the crowd-out rate was approximately $50 \%$.

This paper spurred a large literature on crowd-out in public health insurance programs, much of which found considerably lower crowd-out rates (examples include Blumberg, Dubay, and Norton 2000; Dubay and Kenney 1996; Shore-Sheppard 1996; Shore-Sheppard 2008; and Yazici and Kaestner 2000). Gruber and Simon (2008) trace the evolution of the crowd-out literature in the decade following Cutler and Gruber (1996), noting the large range of crowd-out estimates. They explain this range as due to wide variation in estimation methodologies, data types and even the particular computation of the crowd-out measure. CBO (2007) reviewed the 
literature on crowd-out from CHI-era (generally defined as 1997-2002) expansions, which targeted near-poor children of all ages, and concluded that the crowd-out rate from these later expansions was between 25 and $50 \%$.

Here we focus the relative contribution of our work given that our methodology is substantially different. First, the definition of the crowd-out rate itself is an important point of departure. Cutler and Gruber (1996) identify two approaches to computing it: the ratio of the average change in private coverage to the change in public coverage, or one minus the ratio of the change in the uninsured to the change in public coverage. The two measures differ because some people report having both private and public coverage. The treatment of this overlap is an important source of differences in estimates. ${ }^{2}$ The overlap is sometimes thought of as a measurement issue: either a reporting error on the part of survey recipients or an issue of timing (those who moved from one source of coverage to the other report having both). We have an alternative explanation: we observe that $11.7 \%$ of BagerCare enrollees in fact maintain some form of private insurance coverage for at least a significant portion of their enrollment period. Because of this, we think that the overlap population should be treated as a true overlap in coverage. Here, we report two measures of crowd-out: first, the percentage of new Medicaid enrollees who had private insurance at the time of enrollment; and second, the percentage of those enrollees who dropped their private insurance within six months of enrollment. ${ }^{3}$

Second, crowd-out estimates are sensitive to the data source, especially the use of crosssectional or panel data. In general, papers that use panel data have found lower rates of crowdout. Cross-sectional data, specifically the often-used CPS, suffer from unclear timing (whether the respondent refers to coverage in the past year, as asked, or current coverage). Longitudinal

\footnotetext{
${ }^{2}$ For example, Lee et al. (2008) find no crowd-out using the first approach, but $40 \%$ using the second.

${ }^{3} \mathrm{GAO}(2006)$ also found that a substantial amount of Medicaid enrollees also had private coverage.
} 
surveys like the Survey of Income and Program Participation (SIPP), another common data source in this literature, have the strength of allowing researchers to observe changes in insurance coverage over time. However, most panel data sets, including the SIPP, have comparatively smaller sample sizes and are not designed to be representative at the state level. Administrative data do not suffer from issues of sample size, representativeness, or timing, but have not generally been used in this literature. We found just two studies linked to administrative data: Sommers et al. (2007) and Shone et al. (2008). Both use responses to parental surveys for which potential respondents were randomly drawn from administrative records. Both studies report a ratio of change in private coverage to public coverage of $28 \%$ when all changes in private coverage are factored into the measure. Sommers et al. also report a "substitution" estimate across ten states of approximately $14 \%$ when the numerator excludes cases where coverage is dropped or lost due to changes in employment circumstances impacting coverage, or changes in family circumstances.

Third, methodological differences produce variation in estimation outcomes. Both Dubay and Kenney (2009) and Gruber and Simon (2008) compute a range of estimates using different strategies. Both produce estimates derived under both the instrumental variable and differencein-differences estimation approaches. Using the National Survey of America's Families (NSAF), Dubay and Kenney report 33\% - 43\% crowd-out estimates for children's coverage. Gruber and Simon find 30\%-60\% using the SIPP. Yazici and Kaestner (2000) provide one careful discussion of the impacts of different methodologies and the assumptions required for their validity. A particular strength of our data source is that it allows us to abstract from differences in methodology and identification issues through direct measurement. We also provide 
alternative estimates using a difference-in-differences methodology and CPS data to contrast with our results.

\section{Data}

We use two very different sources of data in this paper: administrative records covering the universe of Medicaid enrollees in Wisconsin and cross-sectional survey data representative of the Wisconsin population. Here, we describe them in turn.

\section{A. Administrative Data}

The main data source is administrative enrollment records from the state of Wisconsin's Medicaid and CHIP programs. These records were made available to us as a part of an evaluation of a state health reform, which occurred in February 2008. The reform, known as BadgerCare Plus or BC+, expanded on BadgerCare (Wisconsin's CHIP and Medicaid). BC+ combined its predecessor programs into one umbrella program. The introduction of $\mathrm{BC}+$ was characterized by the following elements: eligibility expansions; simplification of eligibility rules and enrollment and verification processes; and an aggressive marketing and outreach campaign. Leininger et al. (2011) provide a more in-depth analysis of the $\mathrm{BC}+$ reform and its impacts on enrollment and exit rates.

Most important for our purposes were two changes. First, eligibility criteria were changed for children and parents. BC+ eliminated the income eligibility ceiling for children, which was previously at $200 \%$ FPL. BC+ also expanded the definition of parental eligibility to include low-income caretaker relatives. ${ }^{4}$ Second, restrictions designed to discourage crowd-out were completely lifted for all enrollees under $150 \%$ FPL. Prior to the launch of BC+, anti-

\footnotetext{
${ }^{4}$ Later changes in $\mathrm{BC}+$ expanded coverage to adults without dependent children with incomes of up to $200 \%$ FPL. They are excluded from this analysis.
} 
crowd-out provisions were applied in the BadgerCare program but not in the Medicaid program. Under BC+, applicants with incomes over 150\% FPL are subject to anti-crowd-out provisions. With good-cause exceptions ${ }^{5}$, these individuals face a three month waiting period for dropped coverage and must have no previous offer of employer-sponsored insurance (ESI) during the past 12 months, nor have the opportunity to enroll in ESI in during the upcoming three 3 months. The employer must cover at least $80 \%$ of the premium for the crowd-out provisions to apply.

Reform resulted in a significant increase in enrollment: enrollment of children in $\mathrm{BC}+$ increased by approximately 23,000 people (7\%), and enrollment of adults increased by 28,000 (16\%) in February 2008 alone. From April 2008 on, net enrollment increased on average by more than 5,000 people per month.

For our analysis of crowd-out, we construct a longitudinal administrative dataset from four administrative databases:

- CARES: Wisconsin's program eligibility database;

- UI: Unemployment Insurance and quarterly wage records;

- TPL: Wisconsin's Third Party Liability database; and

- DOL: a U.S. Department of Labor database of all self-insured firms.

The unit of observation in this dataset is an individual-month beginning in the first month that individual enrolled in BC+ between January 2006 and May 2009. ${ }^{6}$ We link across these different sources by using Social Security numbers (SSNs) and federal employer identification numbers (FEINs).

Data on $\mathrm{BC}+$ enrollees were drawn from the Wisconsin enrollment eligibility database system, called CARES, from January 2006 to November 2009. For some of the analysis, we use

\footnotetext{
${ }^{5}$ Good cause exemptions include

${ }^{6}$ We include only new enrollees; all of the enrollees in January 2006 are left-censored, so we cannot observe the start-date of their spells. We exclude these censored observations from our analysis. We use the panel nature of the data to look six months ahead at private status, so although the data go through November 2009, the last new spells we include are those beginning in May 2009.
} 
data from other case members; a case includes all individuals associated with eligibility determination (generally, everyone in the applicant's household). Over this time period, we have monthly enrollment data for a total of $1,392,185$ enrollees in 433,525 unique cases. CARES also contains demographic and income information, including age, sex, ethnicity, citizenship, educational attainment, and income sources. From the income data, we are able to observe whether the main source of income for a case is self-employment.

Individuals are matched to the TPL database using their SSNs. TPL is an individuallevel database that contains all enrollees in state health insurance programs who are covered by a private fully-insured health insurance plan. This database, while an excellent resource for our study on crowd-out, is limited in two ways. First, the database does not contain individuals who are covered by health insurance provided by a self-funded employer (whose policies are not subject to state regulation). Second, these data are available for each month in which an individual is enrolled in $\mathrm{BC}+$, but do not contain information on the health insurance coverage of individuals in months prior to enrollment or following disenrollment. Those enrollees who do not have insurance according to the TPL database either do not have private insurance or have health insurance through a self-funded employer.

To assess whether enrollees may have access to health insurance coverage through a selffunded employer, we connect $\mathrm{BC}+$ cases to their set of employers by linking CARES through SSNs to a database of quarterly earnings records from Wisconsin's unemployment insurance (UI) system. Almost all employers are required to file quarterly wage reports for each employee on the payroll in case of later unemployment claims. The wage reports include the employee's SSN and quarterly wages and the employer's FEIN and industry classification code. Only 
employers not subject to unemployment insurance laws are exempt from reporting. ${ }^{7}$ Employers who are exempt from UI reporting (such as independent contractors) are highly unlikely to be self-insured. Since our enrollment data is monthly, we assign enrollees to a firm in each month within the quarter in which we observe them in UI. Those who work at multiple firms are assigned the FEIN of the employer from which they earned the most in wages. The UI data are available for all workers in CARES both prior to and post enrollment, enabling us to identify workers who had a job loss at the time of enrollment. Of the 433,525 cases in our sample, 286,352 cases have a member that also appears in the UI database. That is, $66 \%$ of our cases have a member who was employed by a UI reporting firm.

Next, for those who do not have a TPL match, we use FEINs (obtained from UI) to link to data from the U.S. Department of Labor (DOL), in order to see if a BC+ case member's employer offers a self-funded plan. We obtained these data through a Freedom of Information Act request. The data represent the universe of employers within the United States from 20032007 that are self-insured for health, life, and disability and related insurance plans. These data are used to administer ERISA, and are acquired as part of the required reporting of self-insured firms to the Internal Revenue Service. Because we are unable to observe which members of a case with a DOL match obtain their health insurance from the self-insured firm, we make the relevant assumptions discussed below in Section 4 regarding self-insured status for all members. Our results are not sensitive to this assumption. In the data, we match roughly $10 \%$ of enrollees to a DOL firm.

For much of the analysis, we separate the data into three time periods: pre-reform (January 2006 to January 2008), transitional (February and March 2008), and post-reform (April

\footnotetext{
${ }^{7}$ In general, WI employers are subject to UI liability if they pay $\$ 1,500$ or more in wages in any calendar quarter or have full or part-time employees working for them in 20 weeks or more during a calendar year. Special rules apply for agriculture, non-profit firms, and employers of domestic service workers.
} 
2008 to November 2009). We do this for several reasons. First, it allows us to compare pre and post reform, although the recession, which began in December 2007 and ended in June 2009 confounds causal inference. Second, we separate the transitional period because we are concerned that these initial enrollees are different. We know that a group of nearly 50,000 eligible parents and siblings of current program enrollees were automatically enrolled in the program in February 2008, many of whom already had private health insurance. We can identify these in the data and examine them separately below. A bigger concern is the possibility that initial program enrollees behaved strategically in waiting to enroll on Medicaid until after the reform had been implemented (because of different cost-sharing provisions, for example). Finally, it is important when analyzing crowd-out by income group because not all groups were eligible for the entire time period.

Means of some variables in the combined data are listed in Table 1. Most notably, the youngest child in the family is under 5 for nearly half of our sample. Almost the entire sample consists of cases under $150 \%$ FPL; as discussed above, much of the new enrollment occurred in populations that were income-eligible even prior to reform. Very few households earn a majority of their income from self-employment (the definition we use for self-employed), although many appear to be full-time workers. We define full- or part-time status by imputation: we compare a worker's quarterly earnings with what they could expect to earn working full-time (35 hours) at minimum wage; workers below that level were considered part-time. ${ }^{8}$

A minor issue involves the usage of FEINs to link data from different sources. FEINs are issued by the Internal Revenue Service for payroll tax reporting. Although a FEIN is unique to a firm, firms can have more than one FEIN if they have more than one location or operate under

\footnotetext{
${ }^{8}$ Previous work found that wage and hours worked information from CARES to be of low quality relative to UI information. See Wolfe et al. (2006).
} 
different names. For single-unit firms (which have only one establishment), there is a one-to-one relationship between the firm and the FEIN. However, multi-unit firms can have more than one FEIN, such as chain stores, although each establishment can be associated with only one FEIN. Because the UI system sometimes cross-verifies data with the IRS, we are confident that FEINs used in the DOL and UI data are correctly matched. Additionally, for a small sample of employers (including one retail chain, one company that owned several chains in the same industry, and one major manufacturer), we were able to directly verify that the FEINs that were submitted to UI and DOL were identical and accurately represented who owned the responsibility for the insurance offer.

\section{B. Survey Data}

We use two sources of survey data in this paper: the Wisconsin Family Health Survey (FHS) and the Current Population Survey Annual Social and Economic Supplement (CPS). We use both the FHS and the CPS to predict the probability of having private health insurance for enrollees with a family member employed by a firm with a self-funded plan. We also use the CPS in our difference-in-difference models of crowd-out.

The 2007-2009 March CPS data have 11,418 Wisconsin respondents in total. ${ }^{9}$ Our analytical sample consists of employed men and women who are 18 to 65 years old. We further limit our sample to those living with at least one under-aged child in the family in order to mimic the Medicaid eligibility criteria in Wisconsin, yielding an analytical sample of 2,685 men and women. $^{10}$ The health insurance question in the CPS asks about coverage sources in the previous year.

\footnotetext{
9 Our difference-in-difference models include the 2010 CPS.

${ }^{10}$ We only consider those workers who were living in a family (defined by CPS) in which at least one relative child (that is, under 18 years old) was present. Workers who were in families without any related child or who were living alone with unrelated children were excluded from our analysis. For multiple-family households, the workers
} 
Estimates of Crowd-Out from Administrative Data

The FHS is a yearly phone survey of households in Wisconsin that includes questions about health status, behaviors, health services, and insurance. It also contains information on demographics and income. We use a question in the FHS that asks about current health insurance coverage to construct the dependent variable. The 2007 and 2008 FHS data have 5,161 respondents in total. We restrict the sample to households headed by workers aged 18-65 and that have one or more children, leaving us with 2,016 observations. Appendix Table A1 contains descriptive statistics of the sample populations from the CPS and the FHS.

\section{Methods}

The following section outlines our approach to answering our research questions:

(1) What is the percentage of new enrollees in public insurance with private insurance coverage at the time of enrollment?

(2) What is the percentage of these new enrollees that dropped their private coverage soon after enrolling?

We discuss our methods for obtaining point estimates and upper-bound estimates of these percentages. We also discuss our use of a difference-in-differences estimation approach using survey data, while highlighting the discrepancies between this method and our administrative data estimation strategy.

\section{A. Estimates of the Percentage of Enrollees with Private Health Insurance Coverage}

We begin by estimating the percentage of individuals that are covered by private, employer sponsored health insurance (ESI) at the time of enrollment. We will refer to this quantity as $\mathrm{P}(\mathrm{ESI} \mid$ enroll) or more simply, $\mathrm{P}(\mathrm{ESI})$. We break this probability into two pieces: the

who were in unrelated sub-families but had no related child in his/her own family would not be included in our sample. 
probability that the enrollee had ESI from a fully-insured firm and the probability that the individual has ESI from a self-insured firm.

$$
P(E S I)=P(\text { ESI at fully-insured firm })+P(\text { ESI at self-insured firm })
$$

The probability of having ESI at a self-insured firm is given by the probability of having health insurance given that a member of the case is employed at a self-insured firm multiplied by the probability of employment at such a firm:

$$
\begin{aligned}
& P(\text { ESI at self-funded firm })=P(\text { ESI at self-insured firm } \mid \text { Employed at self-insured firm }) \\
& \times P(\text { Employed at self-insured firm })
\end{aligned}
$$

We assume that the probability of having ESI at a self-insured firm is zero for those without a case member who is employed at a self-insured firm:

$P($ ESI at self-insured firm $\mid$ Not employed at self-insured firm $)=0$

While this is not literally true because of the availability of retiree health insurance and COBRA, estimates from the CPS suggest that the number of people who obtain such coverage is very low.

Thus, the probability of having ESI is given by:

$$
\begin{aligned}
P(E S I) & =P(\text { ESI at fully-insured firm }) \\
& +P(\text { ESI at self-insured firm } \mid \text { Employed at self-insured firm }) \\
& \times P(\text { Employed at self-insured firm }) .
\end{aligned}
$$

Our strategy is to estimate each piece of equation (1) to estimate the probability that a new enrollee in $\mathrm{BC}+$ was covered by ESI at the time of enrollment. We do this by first calculating whether an enrollee was covered by an insurance plan in TPL in the month of enrollment. We then determine the percentage of enrollees with case members who are employed at firms with self-funded plans. Finally, we estimate the probability of having ESI 
Estimates of Crowd-Out from Administrative Data

conditional on having a case member employed at a firm with a self-funded plan using survey data.

We first calculate a point estimate of the percentage of $\mathrm{BC}+$ enrollees with a case member employed by a firm with a self-funded plan that were covered by that plan. We do this by using the DOL administrative data files to determine whether a case member is employed at a self-insured firm. We then estimate the probability of their being offered health insurance using survey data. To do this, we estimate probit models where the dependent variable is an indicator for employment-based health insurance coverage of the highest-earning worker. We use the 2007-2009 March CPS and 2007-2008 Wisconsin FHS to estimate the predicted probabilities that new BC+ enrollees will have ESI. Both the CPS and FHS contain information on insurance coverage for all household members. We then predict these probabilities over each new enrollee with a case member who is employed at a self-funded firm and take the average predicted probability for each group as the conditional probability. Details of these models and their results are reported in the Appendix.

We also employ an "upper-bound" approach that makes more conservative assumptions. In it, we assume that any enrollee with a case member employed at a large, self-funded firm has ESI coverage. That is, we assume:

$$
P(\text { ESI at self-insured firm } \mid \text { Employed at self-insured firm })=1 .
$$

We consider this method an "upper-bound" estimate because it represents the maximum possible take-up of coverage by workers at self-insured firms. Some employees at firms that offer health insurance are themselves not eligible for health insurance either because they work part-time, are in occupations that are not covered, or have not been at the firm for a sufficient period of time. For example, Farber and Levy (1998) report that in 1997, only 91 percent of workers in firms 
that offered health insurance were eligible for coverage. The bulk of those workers who were ineligible for health insurance were part-time workers.

\section{B. Estimates of the Percentage of New Enrollees who Drop Private Coverage}

Not every person with private health insurance at the time of enrollment in public programs will drop that coverage. Many $\mathrm{BC}+$ enrollees who have private insurance at the time of enrollment are permitted or required to maintain their private coverage. In such cases of dual coverage, $\mathrm{BC}+$ is the payer of last resort. ${ }^{11}$ Since these individuals do not drop their private insurance coverage in favor of public coverage, we most likely do not want to consider them as having been "crowded-out" in our estimates (although they may be making intensive margin adjustments by choosing less comprehensive coverage).

To determine what percentage of enrollees had private coverage at the time of enrollment but subsequently dropped that coverage, we once again use the TPL database that collects information on all individuals with a private source of insurance in the state who are also enrolled in $\mathrm{BC}+$. The State collects these data so it can determine in which cases $\mathrm{BC}+$ is the payer of last resort. We look forward seven months post-enrollment. Those individuals who had coverage at the time of enrollment (month 1), but did not have it in any of the following six months (months 2 through 7) and were still enrolled in BC+ were considered as having dropped

\footnotetext{
${ }^{11}$ This provision is not specific to Wisconsin. We reviewed the websites for each state program to determine which states allow their family and child program applicants to have dual coverage. Most states' websites provided sufficient evidence to determine their dual coverage policy. When this was not the case, we called the state's CHIP program office directly for further information. Nine states allow some sort of dual coverage with their CHIP program: Alaska, Idaho, Indiana, Kansas, Maryland, Michigan, Oregon, South Dakota, and Wisconsin. These dual coverage programs range in breadth from allowing children/families with private insurance to be dually covered, with income restrictions (Alaska, Idaho, Indiana, Kansas, Maryland South Dakota, and Wisconsin), to only allowing dual coverage in cases of underinsurance, again with income restrictions (Michigan and Oregon). Conclusive evidence is lacking for seven states (D.C., Hawaii, Maine, Minnesota, Montana, North Carolina, and Washington). These states' websites are unclear on the subject of dual coverage and phone calls to get more information were unsuccessful. Thirty-four states do not allow any sort of dual coverage. That is, individuals must not have private coverage under any circumstances to be eligible for these programs.
} 
their private coverage. In the case of spells shorter than 7 months, those that drop private coverage prior to disenrollment are counted.

The longitudinal aspect of the UI data allows us to observe job loss and change among employees. Newly enrolled cases with access to private coverage prior to $\mathrm{BC}+$ enrollment, but who simultaneously lose their jobs likely should not be counted as having been "crowded-out.",12 We identify workers who experienced a job loss, defined as going from having a job match in the quarter of enrollment in $\mathrm{BC}+$ to having no job match in the following quarter. We then assign these workers as not having dropped health insurance for the purposes of our estimation.

\section{Estimates by Subgroup}

We estimate the percentages of enrollees who were covered by ESI at the time of enrollment at who subsequently dropped this coverage for a variety of sub-groups and time periods. We examine three time periods - a pre-expansion period (January 2006-January 2008), an initial post-expansion period (February and March 2008), and a post-expansion period (April 2008- November 2009) - and multiple income categories - above and below 150\% FPL, 150200\% FPL, 200\%-300\% FPL, and above 300\% FPL. We also separately examined child and adult enrollees and residents of rural and urban counties. We do not report separate results for parents and children here, as they differed little from one another.

\footnotetext{
${ }^{12}$ We recognize the possibility that obtaining public coverage could in theory induce individuals to reduce their labor supply, which would result in our classifying intentional exits as job losses. Existing literature suggests that this is not a prevalent phenomenon (see, for example, Strumpf 2011). A more likely potential phenomenon is a switch to self-employment induced by receiving public coverage that results in the lack of a longitudinal match to the UI data. This phenomenon would suggest that we are misclassifying some intentional switches to selfemployment as job losses. However, it is debatable whether these switches should be counted in the crowd-out figures, given that being "job locked" in a position with health insurance coverage when one prefers to be selfemployed is widely considered to be welfare reducing (see, for example, Madrian 1994 and Monheit and Cooper 1994).
} 


\section{Estimating Substitution between Public and Private Insurance Using Survey Data}

As discussed above, the vast majority of studies to date have used survey data to estimate the substitution of public coverage for private coverage or the extent to which public coverage crowds-out private coverage. These studies have predominantly used a difference-in-differences approach or a simulated instrumental variables approach.

We also use a difference-in-differences approach to estimate the extent of substitution between public and private health insurance in response to the large increase in $\mathrm{BC}+$ enrollment that occurred following the February 2008 expansion of the program. Compared to the analysis of nationwide expansions of either the Medicaid or CHIP programs, in which expansions were of different sizes and occurred at different times in different states, difference-in-differences is much less amenable to analyzing the recent Wisconsin expansion. The reasons for this are: first, unlike in previous studies, there is only one expansion (Wisconsin in February 2008); and second, it is not clear what states would comprise an appropriate control group. While previous studies have used difference-in-differences to analyze policy changes in a single state using neighboring states as a control (e.g., Card and Krueger 1994), this type of analysis can be problematic because of power and issues of internal validity.

Despite these potential limitations, we do this analysis to depict what one would find using difference-in-differences to analyze the Wisconsin expansion. In particular, we use the CPS to estimate the change in public coverage and in private coverage before and after the expansion. This approach is similar in concept to what has been previously estimated in the literature except in that it examines a single-state expansion.

We estimate the following linear probability models using data from the CPS from the survey years 2007-20010: 
Estimates of Crowd-Out from Administrative Data

(3) $y=\beta_{0}+\beta_{1} *$ Post $+\beta_{2} * W I+\beta_{3} *($ Post $* W I)+\gamma \boldsymbol{X}+\epsilon$

where $y$ is a dummy variable for health insurance status, Post is a dummy variable for 2009, WI is a dummy variable for Wisconsin, the treatment state, and $\boldsymbol{X}$ is a vector of controls. We consider several different measures of health insurance. These are:

(i) Public coverage (Medicaid/CHIP) or both private and public coverage;

(ii) Private Insurance coverage only;

(iii) Private insurance coverage or both private and public coverage; and

(iv) Uninsured.

We also estimate this model for people of different income levels (0-150\% FPL, 150-300\%FPL, $>300 \%$ FPL). We consider carefully the treatment of individuals with both private and public coverage because of the known importance of this issue in the literature. Our preferred specification counts those who report having both types of insurance in both categories.

The proportion of individuals that may have dropped private insurance would be estimated by the ratio of the change in private coverage to the change in public coverage:

$$
C O=\frac{\beta_{3} \mid \text { Private }}{\beta_{3} \mid \text { Public }}
$$

Because macroeconomic trends during this time period would have, by themselves, led to an increase in public coverage and a decline in private coverage, we need to compare these trends with what happened in a set of control states. The identifying assumption here is that the macroeconomic trends are the same in the control states as in the Wisconsin. The control states we consider are (a) Minnesota, (b) Midwestern states excluding Wisconsin, and (c) the rest of the U.S. 


\section{Results}

We report the results of our analysis in this section. First, we show our upper bound and point estimates of the percentage of enrollees with ESI coverage at the time of enrollment, obtained from the administrative data. Second, we present our estimates of the percentage of enrollees who dropped private coverage. Finally, we present the results based on survey data and difference-in-differences.

\section{A. Administrative Data Estimates of the Percentage with Private Insurance Coverage at} the Time of Enrollment

Overall, for all enrollees, we estimate that in the post-BadgerCare Plus expansion period (April 2008-November 2009), 19.9\% of enrollees had private insurance coverage at the time of enrollment. The $95 \%$ confidence interval for this estimate is $18.7 \%$ to $21.0 \%{ }^{13}$ Since this estimate is subject to some error due to the component estimated from survey data (which may or may not be reflected in our confidence interval), we also compute an "upper bound" estimate that suggests that the percentage of new enrollees with private health insurance at the time of enrollment was at most 27.1\% during the April 2008-November 2009 period. These results are presented in Table 2 .

We separately consider the "initial" post-expansion period (February and March 2008) because of the auto-enrollment and initial large jump in enrollment that occurred with program launch. The percentage of new enrollees in those two months that had private health insurance at the time of enrollment was substantially higher - we estimate that percentage to be $33.2 \%(95 \%$ CI $[31.9 \%, 34.4 \%])$.

\footnotetext{
${ }^{13}$ All reported confidence intervals are 95\% normal bootstrap confidence intervals from at least 300 replications. Percentile and bias-corrected confidence intervals are very similar and not reported here.
} 
The percentage of enrollees with private health insurance at the time of enrollment was lower prior to the program expansion (January 2006-January 2008). We estimate this percentage to be $17.3 \%,(95 \% \mathrm{CI},[16.1 \%, 18.4 \%])$. We believe the increase in crowd-out is simply due to the effects of the recession, which began in December 2007.

Table 2 also presents these results stratified by poverty level and by whether the county of residence was urban (defined as Milwaukee, Waukesha, or Dane counties) or rural (all other counties). The time patterns discussed above hold generally for the subgroups as well. Higher percentages of enrollees living in families with higher incomes as a percentage of the federal poverty level had access to private insurance at the time of enrollment. Enrollees living in urban as opposed to rural counties were slightly more likely to have access to private insurance. Table 4 presents sample sizes for each cell.

In order to compute the estimates of ESI coverage for those with a case member employed at a DOL firm, we use the estimates from the health insurance model, described above, to predict the probability of a worker having private health insurance conditional upon his or her employment status. This model is described in the Appendix and its results are reported in Appendix Table A2. Overall, and despite slightly different models, we estimate very similar ESI offerings using both the FHS data and the CPS data. Both the CPS and the FHS estimates suggest that $42 \%$ of enrollees with a case member who worked for a firm with a self-funded plan have ESI. Results reported here were calculated using the CPS.

Because our estimates rely on two very different sources of data - the TPL data for those with coverage through non-self-funded insurance plans and the DOL data and survey data from the CPS for those with coverage through self-funded plans, we separate the sources of the estimates into these two components in Table 3. For example, of the $19.9 \%$ of new enrollees 
between April 2008 and May 2009 that we estimate to have access to private health insurance, 16.3 percentage points had access via a non-self-funded plan (TPL) while we estimate 3.6 percentage points had access through a self-funded plan.

We also calculated these figures separately for children and adults, although we do not report them here because they did not appreciably differ from one another. This is perhaps not surprising because the adults in this study are parents (or caretaker relatives), and children tend to have the same sources of private coverage as their parents. Gruber and Simon (2008) conclude that the crowd-out rate is close to $60 \%$ if the estimate is computed at the family level, and is roughly $30 \%$ when computed at the individual level. We have also performed this estimation at the case level rather than the individual level, using the first month that anyone the in the case was enrolled and the employment status of the highest earner on the case and did not find any important differences. We think this is because we observe directly the insurance liability of the enrollee, and not just information on the policies held as one would typically find in survey data. However, we are measuring crowd-out conditional on enrolling in public insurance, so we do not consider those situations in which, for example, a father drops his own insurance coverage and goes uninsured once Medicaid covers his dependents.

In order to estimate an upper bound for the percentage of newly enrolled cases with access to employer sponsored health insurance at the time they enrolled in $\mathrm{BC}+$, we assume that all enrollees with a case member working at self-funded firms have ESI coverage. The proportion of new enrollees with coverage indicated in the TPL is calculated as before. This yields an "upper bound" estimate of $28 \%$ for all new enrollees in the post-expansion period. That is, we are highly confident that the percent of cases with ESI at the time of enrollment is lower than $28 \%$. 
This is calculated under the assumption that all persons employed at self-funded firms do actually have access. This is a strong assumption, given that we are unsure of a worker's parttime or full-time status at these firms or whether the firms offer insurance to all workers or just to management. However, obtaining this number from such strong assumptions makes us confident that it is indeed an upper bound. In particular, our upper bound rules out many of the larger estimates in the literature. Calculated by time period, we find that a maximum of $44 \%, 47 \%$, and $40 \%$ had ESI coverage for the pre-, reform, and post-periods, respectively.

\section{B. Percentage of Enrollees that Dropped Private Coverage}

We estimate that overall, only $8.4 \%(95 \% \mathrm{CI},[7.5 \%, 9.2 \%])$ of enrollees in the April 2008-November 2009 period dropped private coverage within seven months of enrollment. Moreover, the upper-bound estimate suggests that this percentage was less than $15.6 \%$. This percentage was only slightly higher in the transitional period $-9.2 \%(95 \% \mathrm{CI},[8.3 \%, 10.1 \%])-$ and was lower in the pre- period $-6.5 \%(95 \% \mathrm{CI},[5.8 \%, 7.3 \%])$. These estimates are reported in Table 4.

These estimates of the percentage of enrollees who dropped their private coverage are low compared with estimates from the previous literature. As with the estimates of the percentage of enrollees with access to private coverage at the time of enrollment, the estimates of the percentage that dropped private coverage are higher for those individuals in families with higher incomes as a percentage of FPL and are slightly higher for those enrollees who reside in urban counties. The estimates are also very similar when estimated separately for children and for parents, although we do not report these results here. 
Estimates of Crowd-Out from Administrative Data

\section{Results from Survey Data}

To see how the introduction of BC+ in February 2008 affected aggregate health insurance coverage, we used the 2007-2010 CPS (referring to calendar years 2006-2009). Wisconsin children are eligible for $\mathrm{BC}+$ subject to premium requirements, but since $\mathrm{BC}+$ may have a larger effect on lower-income households, and we find that in practice very few households above $300 \%$ FPL participate in the program, we restrict the sample to households below 300\% FPL.

To provide context for the CPS analysis, we first compared public health insurance program counts in the CPS to those from our administrative data. Using the CPS to calculate the number of Wisconsin residents under 65 who were either children or lived with a dependent child and who had Medicaid at some point during the previous year indicates that there were 577,589 enrollees in 2006 ; 557,341 in 2007 ; 638,422 in 2008 ; and 649,445 in 2009 . These estimated levels of enrollment from the CPS are different from what are reported in our administrative data. In contrast to national estimates of large-scale CPS Medicaid undercount (see, for example, Davern et al. 2009), we find that for all but one year CPS estimates yield a markedly higher count than the $\mathrm{BC}+$ administrative data. The 12-month average of enrollment was 504,750 in the 2006 administrative data; 512,500 in $2007 ; 577,700$ in 2008 ; and 657,800 in 2009. The estimated increase in enrollment according to the CPS also exceeded the increase in enrollment according to administrative data. The CPS suggests an increase of 81,000 people between 2007 and 2008, which is much larger than the difference in the average number of enrollees in 2007 and 2008 from our administrative data, which was 65,200.

In Table 5, we report the estimates from equation (3) and (4) using the CPS. Results for children are in the top panel while results for adults are in the bottom panel. The table reports the coefficient on the interaction term $\left(\beta_{3}\right)$ and its standard error for each separate regression with 
the dependent variables in rows and the control groups in columns. The results show that, for all children, rates of public coverage increased by less in Wisconsin than in Minnesota, the rest of the Midwest, or the rest of the U.S, controlling for demographic characteristics of households. The standard errors on these estimates are quite large, however. Rates of private coverage increased in Wisconsin relative to the control states, except for when compared to the whole U.S. The implied crowd-out rates for children range from 167\% (when the Midwest is the control) to a crowd-in rate of $100 \%$ (when the rest of the U.S. are the control states). We also compute crowd-out rates in which we code anyone with both private and public coverage as having public only. These rates are sometimes wrong signed for both children and adults. Bootstrap biascorrected confidence intervals for the crowd-out ratios are reported in the table in parentheses. The confidence intervals are quite large in all cases, and never exclude zero. This gives us little confidence in these results.

The discrepancy between these CPS results and the bounds from our administrative data are likely due to the small sample sizes in the CPS. It may be that we have selected inappropriate control groups, especially given the economic downturn that was occurring in conjunction with this reform. If the downturn hit Wisconsin harder than Minnesota, for example, this would confound our results. However, it is also possible that survey data would lead to systematically different estimates of crowd-out than would administrative data (because, for example, of known issues in Medicaid measurement). The small sample sizes in the CPS (and resulting large standard errors) prevent us from saying anything definitive about any bias in estimates of crowd-out from survey data, only that it is unlikely to be precise when considering an expansion in just one state. Overall, we believe that our estimates using administrative data 
Estimates of Crowd-Out from Administrative Data

informed by population numbers from survey data provides a much more accurate measure of crowd-out.

\section{Conclusion}

Our estimates, based primarily on administrative data, suggest that the expansions in Wisconsin's BC+ program that took place in February 2008 did not lead to a substantial reduction in private insurance coverage. We estimate that between April 2008 and May 2009, $19.9 \%$ of enrollees had coverage from private health insurance at or around the time they entered $\mathrm{BC}+$. Of this percentage, 11.5 percentage points represent cases that we estimate kept private insurance coverage while on $\mathrm{BC}+$ while the remaining 8.4 percent dropped this private coverage within 6 months. To obtain these estimates, we used a combination of administrative data sources along with survey data from the FHS and the CPS. These estimates are more precise and credible than what one could obtain using survey data alone.

Our estimates are low compared with estimates from both Medicaid and CHIP expansions, which tend to be in the $25 \%$ to $50 \%$ range $(\mathrm{CBO}, 2007)$. Moreover, they are low given that current state policy stipulates that all families below $150 \% \mathrm{FPL}$ are eligible for BC+ regardless of whether they have access to ESI, and all families are eligible if they were required to pay more than $20 \%$ of the total premium associated with an employer's plan. The large increase in public coverage in response to the $\mathrm{BC}+$ expansion, therefore, reduced the ranks of the uninsured or added secondary coverage to families with weak private coverage that elected to enroll. 
It should be noted that these estimates are low compared to those in the literature in part because they are based on panel data and do not include as crowd-out those uninsured individuals who move to public coverage but who, in the absence of the $\mathrm{BC}+$ expansion, might have later moved to the "privately insured" state. This is a limitation of using administrative panel data to construct these estimates.

If the number of people on private insurance is reduced with increased public program eligibility, there are two possible mechanisms: a decrease in the take-up of insurance by individuals, or a decrease in the offering of insurance by employers. Cutler and Gruber (1996) find that only the employee take-up margin is important, consistent with the negative results on firm offer rates of Shore-Sheppard et al. (2000) and Marquis and Long (2003). We are unable to observe directly whether the individuals in our sample discontinue coverage voluntarily - take up public coverage in favor of an offer of private ESI- or because their employers cease to offer it. This is a general weakness of this literature.

We do not claim to capture all dimensions of crowd-out. Specifically, we focus on those individuals who actually enroll in Medicaid and had private insurance at the time of enrollment. If potential enrollees are able to use Medicaid as an implicit insurance plan, available when needed but not necessary to maintain active enrollment in, then we will understate the degree of crowd-out. In this sense, our estimates provide more of a lower bound. We are also unable to account for anticipatory behavior, although much of our sample (all of those under 150\% FPL in the post period) would have no eligibility incentive to drop private coverage and go uninsured prior to taking up Medicaid, as they face no premium cost for public program coverage. Despite these limits, this study has captured the actual number of Medicaid enrollees who substitute public coverage for private insurance and the number of those newly enrolled in the 
expanded public program that come from the uninsured - a dimension that has not been previously understood.

This analysis suggests that using administrative data can yield credible estimates of the fraction of public health insurance program enrollees that have access to private health insurance. Moreover, it suggests that, in contrast to some expectations, increases in public coverage in the post-CHIP era do not necessarily incur widespread substitution for private health insurance. 


\section{References}

Blumberg L, Dubay L, and Norton S. 2000. Did the Medicaid Expansions for Children Displace Private Insurance? An Analysis Using the SIPP. Journal of Health Economics 19(1): 33-60.

Card D, Krueger A B. 1994. "Minimum Wages and Employment: A Case Study of the Fast-Food Industry in New Jersey and Pennsylvania," American Economic Review, 84(4): 772-93.

Dubay L, Kenney G. 1996. The Effects of the Medicaid Expansions on Insurance Coverage of Children. The Future of Children 6(1): 152-161.

Solomon J. 2011. Repealing Health Reform's Maintenance of Effort Provision Could Cause Millions of Children, Parents, Seniors, and People with Disabilities to Lose Coverage. Center on Budget and Policy Priorities, February 2011.

Congressional Budget Office. 2007. The State Children's Health Insurance Program. Congressional Budget Office: Washington DC.

Congressional Budget Office. 2009. Preliminary Analysis of Major Provisions Related to Health Insurance Coverage Under the Affordable Health Choices Act. Congressional Budget Office: Washington DC.

Cutler DM, Gruber J. 1996. "Does public insurance crowd out private insurance?" The Quarterly Journal of Economics 111: 391-430

Davern M, Klerman J, Baugh D, Call K, Greenberg G. 2009. "An Examination of the Medicaid Undercount in the Current Population Survey: Preliminary Results from Record Linking." Health Services Research 44(3): 965-987.

Dorn S. 2011. "The Basic Health Program Option under Federal Health Reform: Issues for Consumers and States." Robert Wood Johnson Foundation State Coverage Initiatives, Urban Institute: Washington, DC, March 2011.

Dubay L, Kenney G. 2009. “The Impact of CHIP on Children's Insurance Coverage: an Analysis using the National Survey of America's Families." Health Services Research 44(6): 2040-2059.

Farber H, Levy H. 2000. "Recent Trends in Employer-Sponsored Health Insurance: Are Bad Jobs Getting Worse?” Journal of Health Economics 19(1): 93-119.

Gruber J, Simon K. 2008. "Crowd-out 10 Years Later: Have Recent Public Insurance Expansions Crowded Out Private Health Insurance? Journal of Health Economics 27: 201-217.

Lee HJ, Tian W, Tomohara A. 2008. “The State Children's Health Insurance Program: Participation and Substitution." The Social Science Journal 45: 382-400. 
Leininger LJ, Friedsam D, Mok S, Dague L, Hynes E, Bergman A, Aksamitauskas M, Oliver T, DeLeire T. 2011. “Wisconsin's BadgerCare Plus Reform: Impact on Low-Income Families' Enrollment and Retention in Public Coverage." Health Services Research, 46: 336-347.

Madrian B. 1994. "Employment-Based Health Insurance and Job Mobility: Is there Evidence of Job-Lock?" Quarterly Journal of Economics 109(1):27-54.

Monheit A, Cooper P. 1994. "Health Insurance and Job Mobility: Theory and Evidence." Industrial and Labor Relations Review 48(1): 68-85.

Serafini MW, Appleby J. 2011. "States May Face Showdown with Feds Over Cutting Medicaid Rolls.” Kaiser Health News Service, February 3, 2011.

Shone LP, Lantz PM, Dick AW, Chernew ME, Szilagyi PG. 2008. "Crowd-out in the State Children's Health Insurance Program (SCHIP): Incidence, Enrollee Characteristics and Experiences, and Potential Impact on New York's SCHIP." Health Services Research 43(1), Part II: 419-434.

Shore-Sheppard L. 1996. Medicaid and Health Insurance for Children: Essays in Empirical Economics. Unpublished Ph.D. dissertation. Princeton University.

Shore-Sheppard L. 2008. "The Effect of Expanding Medicaid Eligibility on Health Insurance Coverage.” The B.E. Journal of Economic Analysis and Policy 8(2: Advances), Article 6. Available at http://www.bepress.com/bejeap/vol8/iss2/art6.

Sommers A, Zuckerman S, Dubay L, Kenney G. 2007. "Substitution of SCHIP for Private Coverage: Results from a 2002 Evaluation in Ten States. Health Affairs 26(2): 529-537.

Strumpf E. In Press. “Medicaid's Effect on Single Women's Labor Supply: Evidence from the Introduction of Medicaid." Journal of Health Economics.

U.S. Government Accountability Office. 2006, September. Medicaid Third Party Liability: Federal Guidance Needed to Help States Address Continuing Problems.. (Publication No. GAO06-962). Retrieved from GAO Reports Main Page via GPO Access database:

http://www.gao.gov/cgi-bin/getrpt?GAO-06-862.

Wolfe B, Haveman R, Kaplan T, Young Cho Y. 2006. SCHIP Expansion and Parental Coverage: An Evaluation of Wisconsin's BadgerCare." Journal of Health Economics, 25: 11701192.

Yazici E, Kaestner R. 2000. Medicaid expansions and the crowding out of private health insurance among children. Inquiry 37 (Spring 1), 23-32. 


\section{Appendix: CPS and FHS Samples and Health Insurance Models}

We report summary statistics or our FHS and CPS samples in Table A1. We also use both data sets to estimate probit models of health insurance coverage. The predictors in the probit models include sex, age, geographic location, age of the youngest child in the family, educational level, self-employment status, occupational industry, firm size, earnings, and federal poverty level (FPL). The FHS has fewer available covariates than the CPS. See table A1 in appendix A for descriptive statistics on the CPS and FHS samples. Except for FPL and age of the youngest child, all variables are employment or demographic characteristics of either the highest earner in a family (CPS) or the reference individual (FHS). These variables were selected and constructed to match with the available information in administrative data. The age of the highest earner is coded into 18-34, 35-54, and older than 54 years old (reference). The educational level of the highest earner is coded into less than high school (reference), high school graduation or GED but no college education, and at least one year of college education. The size of the employer is coded into a dichotomous variable, with less than 100 as the reference group. The yearly earnings of the highest earner are coded into less than $\$ 10,000, \$ 10,000-\$ 14,999$, $\$ 15,000-19,999, \$ 20,000-\$ 29,999$, and more than $\$ 30,000$ (reference). Earnings are inflated to 2009 dollars using the CPI-U. FPL is divided into 150\% and less (reference), 151-200\%, 201$300 \%$, and greater than $300 \%$. We use two indicators to identify the residential counties that are more diverse and highly urbanized: living in Dane county (mainly Madison) and living in Milwaukee or Waukesha counties. ${ }^{14}$ We create a dichotomous indicator for the goods-producing industries, including agriculture/forestry, mining, construction and manufacturing industries in

\footnotetext{
${ }^{14}$ We first intended to separate urban and rural residential areas. Though CPS contains geographic information sufficient for our purpose, the administrative data only have residential county. We thus created two indicators of urban counties in order to match both data sets. We cannot separate Milwaukee from Waukesha in the CPS data.
} 
the major industry code. Age of the youngest child is categorized into being younger than 6, 612 (reference), and older than 12 . We also control for the survey years.

We use probit models to estimate the probability of having private insurance among workers. Appendix table A2 shows the marginal effects from the probit models. Since all variables are binary, the table reports the marginal effects of going from 0 to 1 for each. We obtained similar results from the FHS and the CPS. Our results suggest that residential area, earnings, industry, firm size, educational level, and family poverty levels predict the probability of having private insurance well. The workers from smaller firms and workers in non-goods producing industries are less likely to have health insurance. Earning and FPL are positively associated with having health insurance. The workers living in the two largest metropolitan counties in Wisconsin are more likely to have private insurance than those living in other areas. Self-employment is negatively associated with private insurance. 
Estimates of Crowd-Out from Administrative Data

Table 1. Summary Statistics for Administrative Data

\begin{tabular}{lccc}
\hline & Jan 06 - Jan 08 & Feb 08 - Mar 08 & Apr 08 - May 09 \\
\cline { 2 - 4 } Male & $41.4 \%$ & $43.0 \%$ & $43.4 \%$ \\
Dane County & $5.8 \%$ & $5.1 \%$ & $5.6 \%$ \\
Milwaukee County & $26.6 \%$ & $21.8 \%$ & $23.4 \%$ \\
Youngest child <= 5 & $63.3 \%$ & $60.8 \%$ & $61.5 \%$ \\
Youngest child > 5 and <13 & $23.0 \%$ & $27.7 \%$ & $24.3 \%$ \\
Youngest child 13-18 & $13.7 \%$ & $11.5 \%$ & $14.2 \%$ \\
Adult <34 & $85.6 \%$ & $80.6 \%$ & $82.5 \%$ \\
Adult 34-54 & $13.8 \%$ & $18.1 \%$ & $16.5 \%$ \\
Adult 54-65 & $0.6 \%$ & $1.2 \%$ & $1.0 \%$ \\
Less than High School & $71.2 \%$ & $66.3 \%$ & $74.1 \%$ \\
High School Graduate & $23.2 \%$ & $26.8 \%$ & $20.9 \%$ \\
Some College & $5.6 \%$ & $6.9 \%$ & $5.0 \%$ \\
FPL <= 150\% & $93.1 \%$ & $69.7 \%$ & $81.2 \%$ \\
FPL 151-200\% & $6.7 \%$ & $20.0 \%$ & $13.8 \%$ \\
FPL 201-300\% & $0.2 \%$ & $8.6 \%$ & $4.1 \%$ \\
FPL > 300\% & $0.0 \%$ & $1.8 \%$ & $0.9 \%$ \\
Self Employed & $27.0 \%$ & $36.4 \%$ & $28.8 \%$ \\
Employed (UI match) & $60.1 \%$ & $70.7 \%$ & $64.5 \%$ \\
Of which: & & & \\
Goods Industry & $7.7 \%$ & $11.6 \%$ & $9.6 \%$ \\
Service Industry & $92.3 \%$ & $88.4 \%$ & $90.4 \%$ \\
Full Time & $90.8 \%$ & $94.4 \%$ & $93.8 \%$ \\
Part Time & $9.2 \%$ & $5.6 \%$ & $6.2 \%$ \\
Small (non-DOL) Firm & $76.1 \%$ & $71.0 \%$ & $27.0 \%$ \\
Large (DOL) Firm & $23.9 \%$ & $29.0 \%$ & \\
Number of Observations & 472,772 & 91,975 & \\
\hline \hline Sources: WICARES & & & \\
\hline
\end{tabular}

Sources: WI CARES System, UI System, and Department of Labor

Note: Observations consist of new enrollees; all of the enrollees in January 2006 are left-censored, so we cannot observe the start-date of their spells. We exclude these censored observations from our analysis. Individual-level variables are for the highest earner in the case and, for those cases with no earners, the oldest case member. 


\begin{tabular}{|c|c|c|c|c|c|c|}
\hline & \multicolumn{3}{|c|}{ Estimate } & \multicolumn{3}{|c|}{ Upper Bound } \\
\hline & Jan 06 - Jan 08 & Feb 08 - Mar 08 & Apr 08 - May 09 & Jan 06 - Jan 08 & Feb 08 - Mar 08 & Apr 08 - May 09 \\
\hline \multirow[t]{2}{*}{ All } & $17.3 \%$ & $33.2 \%$ & $19.9 \%$ & $23.9 \%$ & $40.2 \%$ & $27.1 \%$ \\
\hline & {$[.161, .184]$} & {$[.319, .344]$} & {$[.187, .210]$} & & & \\
\hline \multicolumn{7}{|c|}{ By Poverty Level } \\
\hline \multirow[t]{2}{*}{$<150$} & $16.8 \%$ & $29.4 \%$ & $17.7 \%$ & $23.4 \%$ & $33.0 \%$ & $20.7 \%$ \\
\hline & {$[.157, .178]$} & {$[.182, .306]$} & {$[.167, .187]$} & & & \\
\hline \multirow[t]{2}{*}{$>150$} & $24.4 \%$ & $41.8 \%$ & $29.2 \%$ & $30.6 \%$ & $46.8 \%$ & $36.0 \%$ \\
\hline & {$[.230, .257]$} & {$[.405, .432]$} & {$[.278, .306]$} & & & \\
\hline \multirow[t]{2}{*}{$150-200$} & $23.9 \%$ & $42.4 \%$ & $27.6 \%$ & $30.3 \%$ & $49.1 \%$ & $35.6 \%$ \\
\hline & {$[.227, .252]$} & {$[.408, .439]$} & {$[.261, .292]$} & & & \\
\hline \multirow[t]{2}{*}{$200-300$} & $37.8 \%$ & $41.0 \%$ & $32.9 \%$ & $40.2 \%$ & $42.9 \%$ & $36.6 \%$ \\
\hline & {$[.370, .387]$} & {$[.397, .423]$} & {$[.317, .341]$} & & & \\
\hline \multirow[t]{2}{*}{$300+$} & $35.0 \%$ & $39.7 \%$ & $37.0 \%$ & $36.9 \%$ & $40.9 \%$ & $39.0 \%$ \\
\hline & {$[.342, .357]$} & {$[.378, .415]$} & {$[.356, .384]$} & & & \\
\hline \multicolumn{7}{|l|}{ By County } \\
\hline \multirow[t]{2}{*}{ Urban } & $19.1 \%$ & $35.1 \%$ & $21.7 \%$ & $25.9 \%$ & $42.0 \%$ & $29.0 \%$ \\
\hline & {$[.177, .204]$} & {$[.338, .364]$} & {$[.206, .229]$} & & & \\
\hline \multirow[t]{2}{*}{ Rural } & $16.3 \%$ & $32.0 \%$ & $18.8 \%$ & $22.8 \%$ & $39.1 \%$ & $25.9 \%$ \\
\hline & {$[.153, .174]$} & {$[.308, .333]$} & {$[.178, .198]$} & & & \\
\hline
\end{tabular}

Sources: WI CARES System, UI System, and Department of Labor

Note: Tabulations include only new enrollees; all of the enrollees in January 2006 are left-censored, so we cannot observe the start-date of their spells.

We exclude these censored observations from our analysis. We report in brackets $95 \%$ normal bootstrap confidence intervals from at least 300

replications. All differences by column (across time periods) are significantly different from one another at the $95 \%$ level. 
Estimates of Crowd-Out from Administrative Data

Table 3: Data Sources for Crowd-out Estimates

\begin{tabular}{|c|c|c|c|c|c|c|}
\hline \multicolumn{7}{|l|}{ Panel A } \\
\hline \multicolumn{7}{|c|}{ What Percentage of Newly Enrolled Individuals Were Privately Insured the at or near Enrollment? } \\
\hline & \multicolumn{3}{|c|}{ Estimate } & \multicolumn{3}{|c|}{ Upper Bound } \\
\hline & Jan 06 - Jan 08 & Feb 08 - Mar 08 & Apr 08 - May 09 & Jan 06 - Jan 08 & Feb 08 - Mar 08 & Apr 08 - May 09 \\
\hline All & $17.3 \%$ & $33.2 \%$ & $19.9 \%$ & $23.9 \%$ & $40.2 \%$ & $27.1 \%$ \\
\hline \multicolumn{7}{|l|}{ By source } \\
\hline TPL & $14.0 \%$ & $29.5 \%$ & $16.3 \%$ & $14.0 \%$ & $29.5 \%$ & $16.3 \%$ \\
\hline DOL / CPS & $3.3 \%$ & $3.7 \%$ & $3.6 \%$ & $10.0 \%$ & $10.7 \%$ & $10.7 \%$ \\
\hline \multicolumn{7}{|l|}{ Panel B } \\
\hline \multicolumn{7}{|l|}{$\begin{array}{l}\text { What Percenta } \\
\text { Enrollment)? }\end{array}$} \\
\hline & \multicolumn{3}{|c|}{ Estimate } & \multicolumn{3}{|c|}{ Upper Bound } \\
\hline & Jan 06 - Jan 08 & Feb 08 - Mar 08 & Apr 08 - May 09 & Jan 06 - Jan 08 & Feb $08-$ Mar 08 & Apr 08 - May 09 \\
\hline All & $6.5 \%$ & $9.2 \%$ & $8.4 \%$ & $13.1 \%$ & $16.2 \%$ & $15.6 \%$ \\
\hline \multicolumn{7}{|l|}{ By source } \\
\hline TPL & $3.2 \%$ & $5.5 \%$ & $4.8 \%$ & $3.2 \%$ & $5.5 \%$ & $4.8 \%$ \\
\hline DOL / CPS & $3.3 \%$ & $3.7 \%$ & $3.6 \%$ & $10.0 \%$ & $10.7 \%$ & $10.7 \%$ \\
\hline
\end{tabular}

Sources: WI CARES System, UI System, and Department of Labor

Note: Table shows the portion of each estimate that comes from the two potential sources: the third party liability database (TPL) and the Department of Labor data (DOL) with Current Population Survey (CPS) predictions. We first look for a match in TPL, then in DOL if no TPL match is found. While reported here for the total population, relative proportions remain similar by subgroup. Left-censored observations are excluded. 
Estimates of Crowd-Out from Administrative Data

Table 4. What Percentage of Newly Enrolled Individuals Dropped Private Insurance Prior to Disenrolling From BC+ (within 7 Months of Enrollment)?

\begin{tabular}{|c|c|c|c|c|c|c|}
\hline & \multicolumn{3}{|c|}{ Estimate } & \multicolumn{3}{|c|}{ Upper Bound } \\
\hline & Jan 06 - Jan 08 & Feb 08 - Mar 08 & Apr 08 - May 09 & Jan 06 - Jan 08 & Feb 08 - Mar 08 & Apr 08 - May 09 \\
\hline \multirow[t]{2}{*}{ All } & $6.5 \%$ & $9.2 \%$ & $8.4 \%$ & $13.1 \%$ & $16.2 \%$ & $15.6 \%$ \\
\hline & {$[.058, .073]$} & {$[.083, .101]$} & {$[.075, .092]$} & & & \\
\hline \multicolumn{7}{|c|}{ By Poverty Level } \\
\hline \multirow[t]{2}{*}{$<150$} & $6.3 \%$ & $8.6 \%$ & $7.3 \%$ & $12.9 \%$ & $12.2 \%$ & $10.3 \%$ \\
\hline & {$[.055, .072]$} & {$[.076, .096]$} & {$[.064, .082]$} & & & \\
\hline \multirow[t]{2}{*}{$>150$} & $9.3 \%$ & $10.7 \%$ & $12.9 \%$ & $15.5 \%$ & $15.7 \%$ & $19.7 \%$ \\
\hline & {$[.081, .106]$} & {$[.097, .117]$} & {$[.116, .142]$} & & & \\
\hline \multirow[t]{2}{*}{$150-200$} & $9.3 \%$ & $11.0 \%$ & $12.5 \%$ & $15.7 \%$ & $17.7 \%$ & $20.5 \%$ \\
\hline & {$[.082, .105]$} & {$[.098, .122]$} & {$[.110, .139]$} & & & \\
\hline \multirow[t]{2}{*}{$200-300$} & $9.5 \%$ & $9.5 \%$ & $12.9 \%$ & $11.9 \%$ & $11.4 \%$ & $16.6 \%$ \\
\hline & {$[.089, .102]$} & {$[.090, .100]$} & {$[.121, .137]$} & & & \\
\hline \multirow[t]{2}{*}{$300+$} & $10.6 \%$ & $13.3 \%$ & $20.0 \%$ & $12.5 \%$ & $14.5 \%$ & $22.0 \%$ \\
\hline & {$[.099, .112]$} & {$[.125, .141]$} & {$[.191, .211]$} & & & \\
\hline \multicolumn{7}{|l|}{ By County } \\
\hline \multirow[t]{2}{*}{ Urban } & $7.2 \%$ & $10.2 \%$ & $9.2 \%$ & $14.0 \%$ & $17.1 \%$ & $16.5 \%$ \\
\hline & {$[.063, .081]$} & {$[.093, .111]$} & {$[.082, .101]$} & & & \\
\hline \multirow[t]{2}{*}{ Rural } & $6.2 \%$ & $8.7 \%$ & $7.9 \%$ & $12.7 \%$ & $15.8 \%$ & $15.0 \%$ \\
\hline & {$[.055, .070]$} & {$[.078, .096]$} & {$[.070, .088]$} & & & \\
\hline
\end{tabular}

Sources: WI CARES System, UI System, and Department of Labor

Note: Tabulations include only new enrollees; all of the enrollees in January 2006 are left-censored, so we cannot observe the start-date of their spells. We exclude these censored observations from our analysis. We report in brackets $95 \%$ normal bootstrap confidence intervals from at least 300 replications. All differences by column (across time periods) are significantly different from one another at the $95 \%$ level with the exception of the $200-$ 300 income group in the pre-reform and transitional periods. 
Table 5. Difference-in-Differences Estimates of BC+ Introduction on Health Insurance Status and Crowd-Out

\begin{tabular}{|c|c|c|c|c|c|c|}
\hline & \multicolumn{6}{|c|}{ Panel A. Children } \\
\hline & \multicolumn{3}{|c|}{ Difference-in-difference } & \multicolumn{3}{|c|}{ Crowdout Ratio } \\
\hline & $\mathrm{MN}$ & MIDW & U.S. & $\mathrm{MN}$ & MIDW & U.S. \\
\hline \multirow[t]{2}{*}{ Public/Both } & -0.058 & -0.034 & -0.034 & & & \\
\hline & [0.043] & {$[0.033]$} & {$[0.031]$} & & & \\
\hline \multirow[t]{2}{*}{ Private } & 0.017 & 0.022 & -0.002 & -0.29 & -0.65 & 0.06 \\
\hline & [0.042] & [0.032] & [0.043] & $(-.89,3.61)$ & $(-2.09,2.22)$ & $(-2.38,9.01)$ \\
\hline \multirow[t]{2}{*}{ Private/Both } & 0.061 & 0.057 & 0.034 & -1.05 & -1.68 & -1 \\
\hline & [0.043] & {$[0.034]$} & {$[0.032]$} & $(-3.26, .15)$ & $(-14.11, .15)$ & $(-7.31, .723)$ \\
\hline \multirow[t]{2}{*}{ Uninsured } & 0.041 & 0.012 & 0.032 & & & \\
\hline & {$[0.026]$} & {$[0.018]$} & {$[0.017]$} & & & \\
\hline \multirow[t]{4}{*}{ Sample Size } & 5606 & 19112 & 149619 & & & \\
\hline & \multicolumn{6}{|c|}{ Panel B. Parents/Caretakers } \\
\hline & \multicolumn{3}{|c|}{ Difference-in-difference } & \multicolumn{3}{|c|}{ Crowdout Ratio } \\
\hline & $\mathrm{MN}$ & MIDW & U.S. & $\mathrm{MN}$ & MIDW & U.S. \\
\hline \multirow[t]{2}{*}{ Public/Both } & -0.041 & -0.037 & -0.01 & & & \\
\hline & [0.038] & {$[0.029]$} & {$[0.027]$} & & & \\
\hline \multirow[t]{2}{*}{ Private } & -0.002 & 0.025 & -0.002 & 0.05 & -0.68 & 0.2 \\
\hline & {$[0.042]$} & {$[0.032]$} & {$[0.030]$} & $(-2.85,20.11)$ & $(-2.76,2.58)$ & $(-1.52,206)$ \\
\hline \multirow[t]{2}{*}{ Private/Both } & 0.006 & 0.031 & 0.005 & -0.15 & -0.84 & -0.5 \\
\hline & [0.042] & {$[0.032]$} & {$[0.030]$} & $(-2.87,13.42)$ & $(-5.76,1.62)$ & $(-8.72,9.69)$ \\
\hline \multirow[t]{2}{*}{ Uninsured } & 0.042 & 0.013 & 0.012 & & & \\
\hline & [0.032] & [0.023] & {$[0.021]$} & & & \\
\hline Sample Size & 4096 & 14268 & 116219 & & & \\
\hline
\end{tabular}

Notes: Table reports the coefficients on the interaction term of Wisconsin and Post (2009-2010) of separate regressions for each dependent variable (rows) and control (columns). Standard errors of regression coefficients in brackets. Full regressions available on request. Sample includes children and parents or caretakers under the age of 65 who have income under $300 \%$ FPL. DD regressions include controls for family structure and characteristics. Bias-corrected 1000 replicate bootstrap confidence intervals for crowdout ratios in parantheses. 
Table A1. Descriptive Statistics FHS and CPS Samples

\begin{tabular}{lcc}
\hline \hline & FHS & CPS \\
\hline & Mean & Mean \\
Private Insurance & 0.86 & 0.82 \\
Public Insurance & 0.08 & 0.11 \\
Survey Year 2008 & 0.52 & 0.32 \\
Survey Year 2009 & - & 0.34 \\
Male & 0.37 & 0.68 \\
Dane County & 0.08 & 0.09 \\
Milwaukee County & 0.17 & 0.26 \\
Youngest Child <5 & 0.32 & 0.4 \\
Youngest Child 5-13 & 0.51 & 0.26 \\
Highest earner <34 & - & 0.26 \\
Highest earner 34-54 & - & 0.71 \\
Self-Employed & 0.11 & 0.1 \\
Full Time Worker & 0.85 & - \\
Firm with 50 or fewer workers & 0.38 & 0.37 \\
FPL 151-200\% & 0.09 & 0.06 \\
FPL 200-300\% & 0.23 & 0.19 \\
FPL>300\% & 0.56 & 0.62 \\
High School Graduate & 0.33 & 0.29 \\
Some College & 0.67 & 0.66 \\
Goods-producing industry & - & 0.31 \\
Highest earner <\$10k & - & 0.02 \\
Highest earner \$10-15k & - & 0.03 \\
Highest earner \$15-20k & - & 0.03 \\
Highest earner \$20-30k & - & 0.12 \\
\hline \hline
\end{tabular}

Notes: Table shows weighted sample means for the populations used in the probit models, the 2007 and 2008 Wisconsin Family Health Surveys (FHS) and the 2007-2010 Current Population Surveys (CPS). Not all variables were available in both surveys. Unavailable variables are indicated by a dash. Details of sample and variable construction are available in the text. 
Estimates of Crowd-Out from Administrative Data

Table A2. Marginal Effects from Probit Models of P(ESI)

\begin{tabular}{|c|c|c|}
\hline & FHS & CPS \\
\hline \multirow[t]{2}{*}{2007} & - & 0.012 \\
\hline & - & {$[0.02]$} \\
\hline \multirow[t]{2}{*}{2008} & 0.02 & -0.02 \\
\hline & {$[0.02]$} & [0.046] \\
\hline \multirow[t]{2}{*}{ Male } & 0.009 & -0.017 \\
\hline & {$[0.021]$} & {$[0.02]$} \\
\hline \multirow[t]{2}{*}{ Dane County } & -0.042 & $0.069 *$ \\
\hline & [0.046] & [0.035] \\
\hline \multirow[t]{2}{*}{ Milwaukee County } & -0.034 & $0.039 *$ \\
\hline & [0.033] & [0.018] \\
\hline \multirow[t]{2}{*}{ Has child $<=5$} & $-0.042 *$ & -0.018 \\
\hline & {$[0.02]$} & [0.019] \\
\hline \multirow[t]{2}{*}{ Has child $>5$ and $<13$} & 0.014 & -0.023 \\
\hline & {$[0.022]$} & [0.022] \\
\hline \multirow[t]{2}{*}{ Adult $<34$} & - & -0.059 \\
\hline & - & [0.044] \\
\hline \multirow[t]{2}{*}{ Adult 34-54 } & - & -0.015 \\
\hline & - & {$[0.042]$} \\
\hline \multirow[t]{2}{*}{ Earnings $<10 \mathrm{k}$} & - & $-0.306 * *$ \\
\hline & - & {$[0.062]$} \\
\hline \multirow[t]{2}{*}{ Earnings $10-15 \mathrm{k}$} & - & $-0.191 * *$ \\
\hline & - & [0.045] \\
\hline \multirow[t]{2}{*}{ Earnings $15-20 \mathrm{k}$} & - & $-0.123 * *$ \\
\hline & - & [0.037] \\
\hline \multirow[t]{2}{*}{ Earnings $20-30 \mathrm{k}$} & - & $-0.073 * *$ \\
\hline & - & [0.024] \\
\hline \multirow[t]{2}{*}{ Goods Industry } & - & $0.076^{* *}$ \\
\hline & - & [0.019] \\
\hline \multirow[t]{2}{*}{ Self Employed } & $-0.094^{* *}$ & -0.031 \\
\hline & [0.035] & [0.026] \\
\hline \multirow[t]{2}{*}{ Full Time } & 0.011 & - \\
\hline & [0.02] & - \\
\hline \multirow[t]{2}{*}{ Small Firm } & $-0.094^{* *}$ & $-0.074 * *$ \\
\hline & {$[0.024]$} & [0.017] \\
\hline \multirow[t]{2}{*}{ FPL $151-200 \%$} & $0.102 * *$ & 0.029 \\
\hline & {$[0.026]$} & [0.029] \\
\hline \multirow[t]{2}{*}{ FPL $201-300 \%$} & $0.194 * *$ & $0.084 * *$ \\
\hline & [0.03] & {$[0.028]$} \\
\hline \multirow[t]{2}{*}{$\mathrm{FPL}>300 \%$} & $0.280 * *$ & $0.176^{* *}$ \\
\hline & {$[0.021]$} & {$[0.028]$} \\
\hline \multirow[t]{2}{*}{ High School Graduate } & $0.126^{*}$ & $0.069 *$ \\
\hline & {$[0.063]$} & [0.03] \\
\hline \multirow[t]{2}{*}{ Some College } & $0.203 * *$ & $0.124 * *$ \\
\hline & {$[0.062]$} & {$[0.031]$} \\
\hline Observations & 2016 & 2685 \\
\hline
\end{tabular}


Notes: Standard errors in brackets. ${ }^{* *} \mathrm{p}<0.01, * \mathrm{p}<0.05$. This table shows the marginal effects from probit models in the two survey data sets used to predict the probability of private insurance over the administrative data in the calculation of equation 1, the 2007 and 2008 Wisconsin Family Health Surveys (FHS) and the 2007-2010 Current Population Surveys (CPS). Not all variables were available in both surveys. Unavailable variables are indicated by a dash. Details of sample and variable construction are available in the text. 